\title{
Milli-International Unit per Milliliter per Milligram per Meter Squared
}

National Cancer Institute

\section{Source}

National Cancer Institute. Milli-International Unit per Milliliter per Milligram per Meter

Squared. NCI Thesaurus. Code C119400.

A unit of concentration (biologic activity) equal to one milli-international unit per milliliter, divided by milligrams per meter squared. 